\title{
Desenvolvimento Local: Quo Vadis?
}

\author{
Nilton Marques de Oliveira \\ Universidade Federal do Tocantins - Palmas - TO - Brasil \\ ORCID: http://orcid.org/0000-0001-6485-314X
}

\begin{abstract}
Resumo
Este texto analisa o desenvolvimento local em duas vertentes: a primeira numa concepção convencional; e a segunda na concepção avançada. A convencional analisa o desenvolvimento do sistema econômico em escala localizada. Na avançada, o desenvolvimento local é compreendido de forma holística, ou seja, o ser humano é visto como agente transformador na sua própria localidade, tendo como elementos: a participação, a solidariedade, a cooperação e o pertencimento de toda sua evolução histórica e cultural do seu território. Para tanto, utilizou-se de caráter reflexivo teóricoconceitual, fundamentado em uma revisão analítica da literatura. A convencional apresenta a teoria do desenvolvimento do sistema produtivo pautado no aumento da riqueza, bens e serviços. Por outro lado, na avançada o crescimento econômico é apenas coadjuvante para reduzir as privações dos bens materiais. A direção do desenvolvimento local está indo mais na concepção convencional, mas a concepção avançada está ganhando espaço na discussão, sobretudo nas regiões menos desenvolvidas.
\end{abstract}

Palavras-chave: Desenvolvimento local. Sistema socioeconômico. Território.

\section{Abstract}

\section{Local Development: Quo Vadis?}

This study analyzes the local development in two aspects: the first one, conventional conception; and the second advanced conception. The conventional the analyzes economic system development in a local level. In the advanced, local development is understood in a holistic way, that is, human being is seen as a transforming agent in his own locality, taking into account elements as engagement, solidarity, cooperation, and belonging of all his territory historical and cultural evolution. For that, a theoretical-conceptual reflective character was used, on the basis of a literature analytical review. The conventional concept presents the productive system development theory based on the increase in wealth, goods, and service. On the other hand, the advanced, the economic development is only conducive to reducing deprivations of material goods. Local development is more aligned with the conventional concept; however, the advanced concept is gaining space in the discussion, mainly in less developed areas.

Keywords: Local development. Socioeconomic system. Territory. 


\section{Resumen}

\section{Desarrollo Local: Quo Vadis?}

Este texto analiza el desarrollo local de dos maneras: la primera en una concepción convencional; y la segunda en una concepción avanzada. La convencional analiza el desarrollo del sistema económico en escala localizada. En la avanzada, el desarrollo local se entiende de manera holística, es decir, el ser humano es visto como un agente transformador de su propia localidad, teniendo como elementos: la participación, la solidaridad, la cooperación y la pertenencia de toda su evolución histórica y cultural de su territorio. Por lo tanto, se utilizó un carácter reflexivo teórico-conceptual, basado en una revisión analítica de la literatura. La convencional presenta la teoría del desarrollo del sistema productivo basado en el aumento de la riqueza, bienes y servicios. Por otro lado, en la avanzada el crecimiento económico solo se apoya para reducir las privaciones de los bienes materiales. La dirección del desarrollo local va más en la concepción convencional, pero la concepción avanzada está ganando espacio en la discusión, especialmente en las regiones menos desarrolladas.

Palabras clave: Desarrollo local. Sistema socioeconómico. Territorio.

\section{Introdução}

Quo vadis, é uma frase latina que significa "que caminho a seguir?" ou "Aonde vais?". Partindo desta interrogação o artigo propõe discutir o desenvolvimento local em duas vertentes: a primeira analisa o desenvolvimento do sistema econômico em escala localizada (concepção convencional), a segunda, o desenvolvimento local é analisado de forma holística, ou seja, o ser humano é visto como agente transformador na sua própria localidade, tendo como elementos, a participação, a solidariedade, a cooperação e o pertencimento de toda sua evolução histórica e cultural do seu território (concepção avançada). Neste ponto, o objetivo consiste em traçar um quadro dessas duas concepções, sem ter a preocupação de realizar uma exposição dos conteúdos das teorias de desenvolvimento. Atém-se apenas àquelas que tratam de desenvolvimento local, e para tal lançou-se mão da classificação de Palacios (1983)', que divide as contribuições ao estudo do conceito de região em dois grupos fundamentais: as formulações "convencionais" e as "avançadas". Essas contribuições de Palacios serviram de inspiração na construção do debate deste de artigo, assim como fez Breitbach (1986) quando estudou o conceito de região.

O primeiro grupo (convencional) se caracteriza por trabalhar com base na abstração do sistema social que está na origem da formação da localidade e, com isso, formula leis de caráter universal, sem levar em conta o condicionamento histórico do objeto que pretende analisar. Dentro desse grupo estão situadas as chamada Escola Alemã (Weber, Lösch e Christaller), a Escola Francesa (Perroux e Boudeville) e Isard e Marshall. Esses estudiosos, tem em comum a abstração dos fatores sociais sobre a configuração espacial, teve sua origem no seio de uma corrente da mais pura tradição neoclássica, sendo seus autores predominantemente anglo-saxões. Tratando de elaborar um discurso puramente

\footnotetext{
${ }^{1} \mathrm{O}$ agrupamento das concepções feito por Palacios (1983) parece ser o mais simple e o mais claro.
} 
científico e neutro, dedicando-se a desenvolver técnicas e modelos quantitativos e a aplicá-los no que ocorre nas localidades, o principal objetivo nesse momento era o desenvolvimento da região, ou seja, das atividades produtivas, fazendo abstrações do contexto social onde se faz análise, assim como do momento histórico, a atmosfera, a estrutura política e o grupo étnico de que se trate (BREITBACH, 1986).

Por seu turno, o grupo denominado "concepção avançada" se caracteriza, em oposição ao primeiro, por considerar como ponto de partida de suas formulações a existência de um sistema social com determinantes históricos. Esse grupo de concepções incorpora, como consequência desse ponto de partida, a noção de que o local não é um elemento neutro, independente em relação ao tipo de sociedade que ali se estabelece. O sistema social, considerado em sua historicidade, está na origem das concepções avançadas de regiões, uma vez que o padrão de formação de um território está condicionado pelo tipo de relações sociais existentes no interior da comunidade humana que realiza esse assentamento (BREITBACH, 1986). Nesse grupo encontram-se formulações como as de Vázquez Barquero, Figueira, Boisier, Furtado, Becker, Ferrera de Lima, Piffer dentre outros.

Cabe destacar seu caráter reflexivo teórico-conceitual, fundamentado em uma revisão analítica da literatura, para discutir os conteúdos de determinados conceitos de desenvolvimento local de modo a situar o pesquisador dentro do debate atual sobre o tema. Para tanto, procedeu-se à sistematização de algumas ideias de autores considerados relevantes, com o intuito de extrair os elementos comuns de suas análises. Tendo como hipótese que o desenvolvimento local proporciona bem-estar social, integração consciente do cidadão em todo processo de transformação político, cultural, econômico, social e institucional em seu território.

O local ${ }^{2}$, neste texto, é tido como um campo de possibilidades e de experimentação cotidiana de respostas aos desafios levantados pela comunidade. Certamente, a perspectiva é de conquista da sustentabilidade, em suas múltiplas acepções, além de constituir em uma nova cultura de ações voltadas à consecução de objetivos coletivos. O entendimento de desenvolvimento local é repleto de controvérsias, imprecisões, ambiguidades e dificuldades de definição, para as quais sua abordagem requer um leitura crítica dos paradigmas dominantes no campo acadêmico. As reflexões sobre o desenvolvimento local tendem a enfatizar as dimensões antro-sociológicas que existem entre os atores locais. Para este argumento, Mballa (2017) rejeita a tendência de pensar no desenvolvimento local como algo separado, sem contato com o regional, nacional ou global. Para uma compreensão dos desafios do desenvolvimento local, é preciso incorpar na análise vários indicadores que incluem, entre outros, formas de gestão pública, capital social, esforços associativos, relações econômicas cooperativas e redes produtivas, pobreza, o atraso e a marginalização social (AROCENA, 1995, 1997; MBALLA, 2017).

Após essa breve contextualização, a pergunta é: Qual concepção se está tomando na construção do desenvolvimento local? A concepção convencional ou a avançada?

${ }^{2} \mathrm{O}$ conceito de local é usado de forma diversificada, podendo referir-se a um bairro, distrito, município, região, e país. 
Isto posto, este artigo está dividido em cinco partes, além desta introdução. Na segunda analisa-se a concepção convencional do desenvolvimento local, a seguir apresenta-se a abordagem avançada, chamada aqui de "o outro lado do desenvolvimento local”. Na quarta, a contraposição entre as duas concepções. Por fim, não menos importante, as considerações finais.

\section{Concepção convencional do desenvolvimento local}

No contexto desta seção, o desenvolvimento local se refere à identificação e uso de recursos naturais como fonte de matéria prima para produção capitalista, o espaço é fonte de lucro e satisfação das necessidades. Segundo os teóricos da escola neoclassica, o que determina o desenvolvimento de uma localidade é a sua localização geográfica, os custos de transporte, a disponibilidade de insumos (mão de obra qualificada e matéria prima) e as forças aglomerativas. Essas forças são fatores que atuam em conjunto com o ambiente de pesquisas e inovação, com as empresas instaladas na localidade e nas proximidades, os chamados centros aglomerativos (ISARD, 1956; WEBER, 1909; MARSHALL, 1890).

O termo aglomeração, segundo Leme (1982) se refere ao conjunto de unidades produtivas em virtude da presença de economias de escala internas e externas, sendo estas baseadas nas ideia de Weber (1909) e Marshall (1890); as economias internas se referem aos recursos individuais de cada firma e economias externas, são função do desenvolvimento geral da indústria. O conceito de economias externas coincide com o que Hoover (1937) denomina de economias de localização. Com relação a esta última, Isard (1956) mostra que um estudo destas considera as economias de urbanização, definidas como as possíveis economias ou deseconomias de localização presentes em determinado território, no qual estão disponíveis trabalhadores especializados, assim como um significativo mercado composto por compradores e vendedores.

Existem ainda as economias que despontam em razão de maior necessidade de utilização da estrutura urbana, como o sistema de transporte, infraestrutura de água e energia, conectados a uma articulação mais próxima das indústrias. E, por último, as deseconomias que passam a ser relativas a aumentos do custo de vida e dos valores dos salários, nos custos de bens produzidos sob condições de retornos decrescentes e, no valor da renda fundiária urbana. Nesse contexto, é possível identificar que certos municípios podem, em razão do seu nível de desenvolvimento, estar gerando forças centrípetas ou centrífugas, atraindo ou repelindo atividades econômicas. Assim, a capacidade de um centro urbano acompanhar o desenvolvimento da sua capacidade produtiva passa a ser fundamental para a presença contínua de forças de atração.

Seguindo a mesma linha de pensamento, Lösch (1940) partiu para o desenvolvimento da sua teoria que buscava explicar o surgimento da hierarquia de cidades. Esta procura incorporar ao raciocínio ideias relacionadas à teoria da localização das atividades econômicas, demonstrando como, a partir dessas localizações, haveria uma tendência ao aparecimento do sistema de lugares centrais. Lösch (1940) consegue traçar uma dinâmica produtiva e econômica por meio de seu modelo, que conduz à formação de uma área de mercado em função dos custos de produção juntamente com os custos de transportes e a capacidade 
de ampliação das economias de escala que os produtores passam a gerar. Estas últimas favorecem a expansão dos municípios, em razão da expansão das atividades produtivas, possibilitada pelo crescimento de suas respectivas áreas de mercado. Assim, verifica-se a formação de um sistema de cidades em que é possível identificar, em função da geração de economias de escala e de custos de transportes, uma hierarquização urbana, sendo esta decorrência direta da capacidade de acumulação e formação de capital (LEMOS, 1988; SIMÕES, 2003).

Indo nesta mesma temática, Perroux (1955) e Boudeville (1970) formularam no século $X X$ os conceitos de espaço econômico e polos de crescimento. No conceito de polos de crescimento os autores tiveram visões diferentes. Para Perroux (1955) polos de crescimento em uma localidade surgiria de maneira natural, a partir de um crescimento econômico originado de desequilíbrios e dominação, que ocorrem irregularmente. De outro lado, o conceito de polo de crescimento desenvolvido por Boudeville (1970) foi elaborado com base no conceito de espaço geográfico, no qual um conjunto de indústrias em expansão induz, futuramente, o desenvolvimento de atividades econômicas por intermédio de sua área de influência. Com o intuito de diagnosticar a formação de uma rede urbana, Christaller (1933) procurou estudar as causas que levavam as cidades a se organizarem em uma espécie de rede. Questionava o porquê da existência de pequenas e grandes cidades e, ainda, o motivo pelo qual estas estavam distribuídas de forma irregular no espaço. Em razão dessa análise, surge a ideia de lugar central, fruto do conceito de centro de uma região no qual a densidade de localização da população e das atividades produtivas é superior à da região complementar.

As iniciativas de desenvolvimento regional/local surgiram a fim de neutralizar os efeitos negativos que a globalização e o ajustamento produtivo causaram no padrão de vida da população (VÁZQUEZ-BARQUERO, 2009). Na América Latina, por exemplo, o crescimento econômico não tem sido acompanhado por um aumento de equidade ou pela redução da pobreza no nível local. De fato, é um sinal de que, à medida que as economias locais, regionais, nacionais e internacionais são reestruturadas e transformadas, novas formas de organização social são criadas; as economias modernas tentam reagir a essas formas inovadoras de organização para se conectarem com os desafios de um mundo cada vez mais competitivo, individualista e interdependente (ENRIQUEZ, 2011; MBALLA, 2017). Na Europa, nos anos 1990 surgiram inumeras iniciativas para sustentar a economia local, por agentes públicos e privados que responderam às necessidades da economia e da sociedade, com a implantação de novos modelos de intervenção local, para fortalecer o desenvolvimento endógeno (PAUNERO, SANCHEZ e CORONA, 2007).

Tanto Ferrera de Lima (2003; 2010) quanto Oliveira e Piffer (2016) compreendem o desenvolvimento regional/local como uma análise de fatores sociais e econômicos no interior de uma região, fatores esses que compõem a mobilidade espacial do capital, do trabalho e das inovações tecnológicas. Tais fatores, quando bem empregados em uma determinada localidade, podem reduzir ou acelerar as desigualdades sociais e econômicas. A estratégia de desenvolvimento deve ser considerada caso a caso, uma vez que as necessidades e demandas das localidades são diferentes, as capacidades dos habitantes, empresas e comunidade local mudam e, além disso, cada comunidade pode ter uma visão diferente das prioridades que devem incorporar as políticas de desenvolvimento. A região deve 
ser identificada por sua estrutura econômica; ela se caracteriza pelo maior ou menor dinamismo de crescimento. Áreas dinâmicas tendem a atrair fatores de produção e a crescer ainda mais rapidamente, enquanto que regiões com problemas estruturais perdem populações e capitais (LOPES, 1984; FERRERA DE LIMA, 2003; 2010).

$\mathrm{Na}$ vertente convencional, o desenvolvimento é visto sob dois aspectos: o primeiro o caracteriza como exógeno, em que o processo de desenvolvimento depende da efetiva intervenção do estado ou de agentes econômicos de fora das regiões; e no segundo, o desenvolvimento é endógeno, também chamado de local. O modelo de desenvolvimento local centrado no Estado se caracteriza como sendo um desenvolvimento de "cima para baixo", neste caso os atores locais deixam de ser protagonista, passando a ser coadjuvante, e as vezes expectadores nesse processo o Estado tende a ser indutor dos investimentos, seja básicos ou produtivos, desta feita facilita a entrada do capital regional, nacional e global. A capacidade de acumulação e formação de capital numa localidade depende do seu potencial endógeno que podem ser de origem individual, familiar ou comunitária (bairro ou cidade), no entanto fatores econômicos, sociais, culturais e institucionais são decisivos para o desenvolvimento local. Este deve ser proposto como uma ferramenta para melhorar as condições de vida da população, por meio de ações conjuntas entre o público e o privado, aproveitando os recursos endógenos existentes de forma mais eficiente, eficaz e sustentável (PIKE, RODRÍGUEZ-POSE e TOMANEY, 2007).

\section{0 outro lado do desenvolvimento local: concepção avançada}

O termo desenvolvimento local tem sido associado à noção de progresso material e de modernização tecnológica. Sua ascensão, mediante a desconsideração das diferenças regionais, culturais e desrespeito à sabedoria local tem em sua sutileza, no seu interior, o domínio e a imposição de outras culturas que desequilibram a sociedade local. Para Verhelst (1992) a história do desenvolvimento, na qual se atribui importância secundária à dimensão cultural, estão presentes mentalidades etnocêntricas, evolucionistas e racionalistas. O desenvolvimento local associado ao progresso material decorre de uma visão positivista que mira apenas o crescimento de taxas e indicadores econômicos. Harvey (2013) acrescenta a crença do progresso linear e tecnicista, características, aliás da modernidade. Compreender o desenvolvimento, de fato, não se atém apenas à questão conceitual, mas de postura, valores e sentimento, sustentados pela modéstia e simplicidade. A abordagem humanista do desenvolvimento local está ligada à valorização das pessoas em sua essência, em sua plenitude, que tem o crescimento econômico como meio de reduzir suas privações e as aflições humanas a la Sen $(2000,2008)$. Nessa mesma linha Max-Neef; Elizalde; Hopenhayn (1986) advogam que o desenvolvimento deve voltar-se para as pessoas e não para os objetos.

Martins (2002) propõem a participação das pessoas em todo o processo de desenvolvimento, desde o planejamento à sua implementação, e mesmo que resultem em melhorias efetivas das condições matérias de vida, são insuficientes para assegurarem a continuidade do processo, pois o verdadeiro diferencial do desenvolvimento local não se encontra em seus objetivos (bem-estar, qualidade de 
vida, endogenia, sinergias), mas na postura que atribui e assegura à comunidade o papel de agente e não apenas de beneficiária do desenvolvimento.

O desenvolvimento local proporcional à abordagem holística deve ser entendido como a satisfação das necessidades humanas fundamentais por meio do "protagonismo real e verdadeiro de cada pessoa" (MARTíN, 1999, P. 172). Entendese que criar as condições para que a comunidade efetivamente exerça este protagonismo, se afigura como o maior desafio para que o desenvolvimento aconteça, considerando que, diferentemente dos países "ricos", nos países em processo de desenvolvimento persistem algumas ausências importantes como: a cidadania, a identificação sociocultural e territorial e o sentido de vizinhança. Boisier (2001), ao levantar a preocupação da terminologia do desenvolvimento, afirma que há uma crescente adjetivação do termo desenvolvimento, que muitas vezes provoca mais confusão do que esclarecimento.

Segundo Moura et. al (2003), o desenvolvimento local compreende o combate à exclusão social como eixo norteador, e suas ações tendem a priorizar os pequenos empreendimentos e os segmentos que estão à margem do grande mercado. Neste sentido, quando se fala em desenvolvimento de forma concreta, é válido lembrar que é constituído de desenvolvimento social, humano e sustentável, aonde se busca a melhoria da vida das pessoas e da sociedade como um todo. $\mathrm{O}$ conceito de desenvolvimento local tende a ser cada vez mais interpretado como a conquista de condições culturais, institucionais, éticas, políticas e certamente econômicas, que promovem a transformação do homem em verdadeiros seres humanos dotados de dignidade, subjetividade, sociabilidade e transcendência em que coexistem suas características biológicos e espirituais, esses últimos produtores de conhecimento, do saber e do amor. O desenvolvimento local é então intangível e subjetivo, tem mais a ver com o ser do que com ter, embora nunca possa ser concebido sem superar as mais óbvias deficiências concretas (BOISIER, 2001).

Furtado (1996) diz que a ideia de desenvolvimento assentado no crescimento econômico é um simples mito, posto que deixa de lado a tarefa essencial de identificar as necessidades fundamentais da coletividade, para valorizar os investimentos, as exportações e o crescimento. Indo nesta mesma direção Boisier (2007) completa dizendo que o desenvolvimento é uma utopia. Tanto Furtado (1996) quanto Boisier (2007) afirmam que alcançar o desenvolvimento pleno é abstração, longe da nossa realidade, é um sonho quase intangível. Boisier (2004) complementa ainda, que a solidariedade deve estar presente no território, para ele a solidariedade envolve o reconhecimento do ser humano como pessoa humana em sua dupla condição de individualidade e sociabilidade, isto é, como sujeito de seu próprio destino sempre alcançado em associação com outros, assim se pratica a verdadeira solidariedade, que nada mais é, que a expressão prática do amor, no sentido amplo.

Analisando a participação da comunidade na construção do desenvolvimento local Martins (2002) afirma que o envolvimento é empenho pessoal, um aprendizado difícil, no entanto é necessário fazer ouvir, entender e atender, estando, portanto, sujeito à fatores históricos e culturais. A participação parece manter uma relação direta com a capacidade individual ou coletiva de interagir, cooperar, associar-se e confiar, isto é, com o chamado capital social (COLEMAN, 1990 e 1998; BOURDIEU, 1989, 1998; FUKUYAMA, 2002; PUTNAM, 
2007). Embora complexo e conceitualmente ainda impreciso, o capital social assume patente visibilidade enquanto recurso potencial de desenvolvimento, tanto mais pelo fato de que tem seu aporte na dimensão cultural e não apenas sociológica ou espacial.

Essa abordagem também considera a importância do capital social e os vínculos de cooperação com agentes externos para melhorar os recursos humanos, técnicos e monetários, entre outros, que contribuem para a implementação do desenvolvimento local. Becker (2002, p.23), argumenta que regionalizar, localizar, territorializar as dificuldades, os problemas é funcional ao sistema capitalista. "[...] não se tem nenhuma ilusão, nenhuma fé, de que, por exemplo, a 'regionalização' disso ou daquilo seja melhor ou pior, para beltrano ou cicrano".

Para promover o desenvolvimento local de maneira adequada e efetiva é necessário investir em vários tipos de capital (humano, social, natural, entre outros) de maneira equilibrada. A produção econômica estará aumentando e democratizando o acesso às riquezas e ao conhecimento, incrementando o poder da população e proporcionando a participação nos bens e serviços públicos e no processo de tomadas de decisão da sociedade. Algumas questões são quase obrigatórias para algum diagnóstico e/ou proposição de política quando se trata de desenvolvimento local. Talvez, a mais importante seja se existem conexões fundadas em um conjunto de virtudes socioeconômicas especiais no âmbito das relações sistêmicas presentes nas articulações socioprodutivas relevantes em clusters específicos (FERREIRA, et al, 2011). Essas articulações tendem potencializar a região e apontar caminhos para incremento de sua competitividade integrando e formando parcerias entre empresas, comunidade e poder público.

Figueira (2011) diz que o processo de desenvolvimento local tem por base cinco princípios: i) o local (território + comunidade) deve, no quadro da sua identidade própria, ser visto e lido pelos membros da comunidade como o centro do universo; ii) a participação e cooperação de todos os atores locais (indivíduos, grupos e organizações) constituem condição sine qua non para o sucesso de qualquer processo de desenvolvimento local; iii) a integração (a nível local) de todos os setores de atividade gera dinâmica e sinergia essencial para o processo de desenvolvimento local.; iv) as questões e problemas locais e o processo de desenvolvimento local devem ter uma gestão local; v) a estratégia de desenvolvimento local deve estar inserida nas dinâmicas globais.

O desenvolvimento local é percebido como resultado da ação articulada sob diversas dimensões (econômica, social, cultural, política e ambiental), bem como de diversos atores (públicos ou privados) existentes no local, ou seja, a visão integrada de todas essas dimensões e a inserção de diferentes atores sociais deve ser internalizada na elaboração de políticas públicas para o desenvolvimento local. Nesse processo, não menos relevante é a presença do Estado e do mercado no contexto de um processo mais amplo de colaboração (ABDALLA e FARIA, 2014).

Piffer et al. (2007), destacam que o processo de desenvolvimento não deve ser realizado exclusivamente para o mercado, mas para a população e suas comunidades. A falta de interação entre o capital social não é boa para a região, dessa forma o desenvolvimento deve ser visto como um processo endógeno movido pela participação, pelo capital social e pela cooperação. Assim, a participação não pode ser vista como um mero requisito metodológico na 
estratégia de sensibilização ou conscientização popular. Ela é muito mais do que um atributo do diagnóstico ou um recurso da ação planejadora. Negligencia-se a participação mesmo quando se empreendem todos os esforços em oferecer às pessoas a oportunidade ampla e irrestrita de participar (MARTINS, 2002). Por exemplo, o esvaziamento de uma reunião pode não expressar desinteresse, mas ser um indicativo importante de que o seu conteúdo não foi perfeitamente entendido ou aceito. Neste sentido, participativo não é o processo em que apenas se assegura a oportunidade da participação, mas aquele que a promove em todos os sentidos, porque nela deposita sua própria condição de vitalidade. Isto significa acreditar muito mais nas pessoas do que estamos acostumados, possibilitando e condicionando sua participação qualitativa e não apenas quantitativa.

O desenvolvimento local passa necessariamente pela análise das questões suscitadas pelas narrativas identitárias regionais, isto é, a chamada identidade cultural, pela naturalização da identidade frente à globalização. A região é o último recurso de estabilidade e de reconhecimento no desenvolvimento. Dessa forma, são necessárias a discussão e a análise da identidade regional sob a ótica da diferença. (PIFFER et al, 2007).

As relações entre os seres humanos e o território condicionam o processo de desenvolvimento de qualquer local, diz Figueira (2017), de fato qualquer processo de desenvolvimento local deve ser dirigido e implementado pelos próprios residentes para que possam reedificar, de forma inovadora e criativa o território que vivem, sem contudo, deixar apagar as características de identificação e coesão em relação ao seu território, cultura e forma de viver. Aponta Figueira (2017) para a necessidade imperiosa de promover estratégia de desenvolvimento local, para isto é preciso uma profunda mobilização das comunidades locais para tomar em suas mãos o planejamento e implementação de políticas públicas de forma integrada e participativa, preservando, assim, sua cultura e o relacionamento com o território.

A estratégia de desenvolvimento local deve ser centrada nas necessidades e aspirações das pessoas e ser orientada para criar sinergias complementares entre os recursos potenciais existentes. Uma estratégia de desenvolvimento é a participação ativa das pessoas pautada nos relacionamentos entre os atores locais e o território onde vivem e trabalham, sendo a única maneira de atrair pessoas e criar projetos de vida estáveis para aqueles que residem no território. Para Figueira (2011, 2017) estes são os motivos pelos quais se pode dizer que o processo de desenvolvimento local pode ser visto como promotor de capital social numa comunidade. Martins (2002) argumenta que o desenvolvimento local é uma questão de escala territorial.

O entendimento da escala local, como aquela que permite a eficácia das ações e um melhor acompanhamento dos resultados, está associado ao fracasso de um modelo de desenvolvimento centrado na industrialização a todo custo, no consumo de massa, no alto custo ambiental e social, viabilizado por ampla disponibilidade de capitais (LEROY, 1997). Contrário a este argumento, tem-se uma nova concepção de desenvolvimento, que valoriza o local como referência territorial (sentido de lugar) aproximando as pessoas, apoiando-se na solidariedade comunitária, envolvendo-a efetivamente na superação dos problemas e na promoção do desenvolvimento humano. A seguir apresenta uma breve comparação 
entre a visão capitalista (convencional) versus a holística (avançada) do desenvolvimento local.

\section{Contraposição da concepção convencional versus a avançada}

As duas concepções apresentadas contribuem para a discussão do assunto, evidentemente com posicionamento diferente. A visão progressista (convencional) apregoa um desenvolvimento pautado no crescimento do sistema produtivo, aumento das riquezas materiais e abrangência do produto local ao global. Já o desenvolvimento local centrado no ser humano, analisa as questões de cunho subjetivo, holístico, ligado à valorização do homem em sua totalidade e que o crescimento econômico é, apenas, coadjuvante para reduzir as privações dos bens materiais. O Quadro 1 sintetiza as características dessas duas vertentes, em que a concepção convencional valoriza, sobremaneira, o individualismo; incentiva o consumismo.

Quadro 01 - Síntese das características do desenvolvimento local: concepção convencional frente à avançada

\begin{tabular}{|l|l|}
\hline \multicolumn{1}{|c|}{ Concepção convencional } & \multicolumn{1}{c|}{ Concepção avançada } \\
\hline Individualismo & Coletivo o indivíduo é original e singular \\
\hline Incentivo ao consumo & Incentivo ao consumo consciente \\
\hline Desenvolvimento vertical & Desenvolvimento horizontal \\
\hline Desenvolvimento exógeno & Desenvolvimento endógeno \\
\hline Degradação ambiental & Preservação ambiental. \\
\hline Democracia representativa & Democracia participativa \\
\hline Desumaniza & Libertação \\
\hline Fragmentação & Integração \\
\hline Rede global & Pertencimento \\
\hline Valorização dos saberes globais & Valorização dos saberes locais \\
\hline Reconhecimento do objeto & Reconhecimento do sujeito \\
\hline
\end{tabular}

Fonte: elaboração própria.

Na concepção convencional o desenvolvimento é vertical, ou seja, de cima para baixo, com pouca ou nenhuma participação nas decisões do sistema produtivo local; é exógeno, isto é, pauta nos investimentos externos, sejam eles oriundos do Estado ou do capital privado (regional, nacional ou global) para a localidade; concepção do desenvolvimento destrutivo das suas reservas ambientais; a democracia é tida como representativa; é um sistema que de certa forma oprime e desumaniza; o sistema de produção é fragmentado, com produção desde ao local ao global e tendendo a valorizar o conhecimento global, em detrimento do saber local.

Já a concepção avançada é mais humana, mais solidaria com os problemas que aflige a comunidade local; incentiva o consumo consciente; o desenvolvimento é horizontal e endógeno; tem em pauta a preservação do meio ambiente, do extrativismo sustentável; a democracia é tida como participativa; sua característica 
é libertadora, preza a integração, o pertencimento, valoriza os saberes locais e por fim reconhece o sujeito como meta do desenvolvimento.

Como visto, a concepção avançada é bem distinta da convencional, está centrada no racionalismo objetivista e cartesiano em valores materiais, adepta ao consumismo, ao progresso material (acúmulo de riquezas), pessoal ("ganhar a vida") e ilimitado ("quanto mais melhor"). O desenvolvimento local centrado na vertente holística (avançada) é considerado, um evento sui generis, resultante do pensamento e da ação à escala humana, que confrontam o desafio de enfrentar problemas básicos e alcançar níveis elementares e auto referenciados de qualidade de vida na comunidade. É certo que compreender o desenvolvimento local requer, indispensavelmente, que se reflita sobre conceitos básicos que, em última análise, estão diretamente implicados no cenário formado pela própria dinâmica da vida.

A concepção holística serve como potencial analítico para uma compreensão da totalidade socioespacial, deve fugir à tentação funcionalista de considerá-la como um organismo vivo. Pode ela ser vista e estudada como um sistema, sendo deste modo equiparada a uma organização cuja estrutura, em interação com o meio ambiente, é obrigada a uma constante mutação; a interação com o meio supõe, simultaneamente, a adaptação e a ação no processo ininterrupto de busca do equilíbrio (em si e com o meio), condição aliás indispensável de sua continuidade. Internamente, o "sistema social" determina os papéis e uma ordem a ser cumprida pelos indivíduos (BRITO, 1986). A questão é complexa e, portanto, de difícil tratamento. Todo esforço para não "naturalizar" o que é social e histórico não será em vão. Não obstante, uma abordagem sistêmica da realidade pode ser mais apropriada à apreensão da totalidade socioespacial, do movimento e da transformação historicamente contínuos. As tensões sociais, a subversão da ordem pela vontade pessoal e o desencontro entre o geral (social) e o individual não devem ser encarados como "disfunções" do sistema social, mas como forças internas que atuam dialeticamente no processo evolutivo incessante de todo e qualquer sistema.

Para superar a concepção convencional do desenvolvimento local, supõe-se buscar uma visão integrada que se aproprie da realidade socioespacial. Capra (1982) assinala que uma crise está promovendo mudança de paradigma, que marca a superação da concepção mecanicista-positivista pela holística-integrada. Para este autor, uma compreensão apropriada do mundo atual, dos seus inúmeros problemas, não pode se dar sem uma nova visão da realidade, uma mudança fundamental em nossos pensamentos, percepções e valores. Fecha-se, assim as características do desenvolvimento local com enfoque convencional versus a avançada.

\section{Considerações finais}

Pretendeu-se com este debate analisar o desenvolvimento local em duas concepções: convencional e avançada. Tais considerações terão, portanto, um caráter conclusivo, porém não definitivo, devido ao próprio caráter de produção científica, cujo processo de avanço encerra constantes superações. Primeiro, compete reforçar que o conceito de desenvolvimento não é único, uma vez que ele não abarca uma única forma de entendimento. A definição de desenvolvimento que 
se julga ser o mais adequado, não é aquele que descreve uma realidade fixa. Mas, ao contrário, é uma definição que expressa um movimento dinâmico em direção a uma realidade local, no sentido de desvendá-la e penetrá-la, portanto, no âmago do seu ser em movimento.

Com relação às considerações efetuadas na concepção convencional, salienta-se que esta considera o campo de análise neutro, sem levar em conta a trajetória histórica da localidade, tem sua origem nas teorias neoclássica aonde os modelos e técnicas quantitativas predominam na análise, nesses moldes um planejamento não pode se mostrar eficiente. Para que ele surta efeito sobre a realidade do local, é necessário, antes de mais nada, averiguar a trajetória histórica dessa realidade para perceber em que direção ela se move e só assim poder propor medidas transformadoras. Para esse grupo de estudiosos o que determina o desenvolvimento de uma região é a sua localização geográfica, o custo do transporte, a disponibilidade de matéria prima, em que os recursos naturais são fonte para a produção de mercadoria e o objetivo principal é a extração da maisvalia.

Já o grupo de autores que discute o desenvolvimento numa vertente mais humana, se caracteriza por considerar como ponto de partida de suas formulações a existência de um sistema social com determinantes históricos, o local não é neutro, pelo contrário é dinâmico e, estar em constante mudança. Leva em consideração a cooperação entre os atores locais, o capital social, tendo como meta promover a qualidade de vida dos moradores e reduzir as desigualdades sociais, no entanto não deixa de levar em conta o mercado local e o global. É articulado sob diversas dimensões: social, cultural, política, institucional e a econômica.

Dito isto, as duas concepções contribuem para o debate do tema, com posicionamento diferente em relação a localidade. A convencional desenvolve a teoria do desenvolvimento do sistema produtivo pautado no aumento da riqueza, bens e serviço. Por outro lado, a avançada parte do princípio de que o desenvolvimento local deve ser voltado para o ser humano, analisa as questões de cunho subjetivo, holístico, e que o crescimento econômico é, apenas coadjuvante para reduzir as privações dos bens materiais.

Com relação às perguntas lançadas neste trabalho, conclui-se, que o desenvolvimento local está indo na direção que prevalece o capital, a riqueza, o crescimento, no entanto a concepção avançada está ganhando espaço na discussão, sobretudo nas regiões menos desenvolvidas, despertando outros pesquisadores a trabalhar o desenvolvimento local de forma holística onde aspectos de identidade cultural, preservação ambiental e pertencimento local sejam levados ao centro do debate.

Em qualquer discussão sobre a temática deve-se, incentivar a participação da população, desde o planejamento até a sua efetiva implementação das ações; a participação efetiva da comunidade deve ser condição sine qua non para promoção do bem-estar e qualidade de vida; a solidariedade, a união, a confiança e a cooperação devem estar presentes entre os moradores locais, dessa forma, se promove a participação de todos os atores na construção do desenvolvimento local; em relação a segunda pergunta sobre o debate acadêmico, verificou-se a predominância da concepção convencional do desenvolvimento com vertente 
capitalista, apesar que, a concepção avançada (humanista) está ganhando força na academia,

Está claro que o desenvolvimento local não é um receituário de medidas prontas, tampouco padronizadas, para serem aplicadas em qualquer lugar, mas uma estratégia de ação coerente com os princípios humanos. O desafio maior é, certamente, criar e consolidar uma outra cultura de desenvolvimento, cujo objetivo maior é o bem-estar psicossocial. Por certo, há um longo e tortuoso caminho a percorrer. É preciso rever algumas de nossas crenças e convicções. Para além disso, a estratégia de desenvolvimento local deve ser centrada nas necessidades e aspirações das pessoas e ser orientada para criar sinergias complementares entre os recursos potencias existentes. Esta estratégia deve ter o envolvimento ativo das pessoas e baseada nos relacionamentos entre os atores locais e o território ondem vivem e reproduz sua força de trabalho, é uma das alternativas de atrair pessoas e elaborar projetos de vida mais humanos.

Finalmente, o desenvolvimento local é um processo lento, porque as comunidades e as instituições precisam de tempo para compartilhar a abordagem de desenvolvimento pautada na valorização do homem e da natureza. Fica posta, portanto, a necessidade de ampliar e aprofundar o debate sobre o desenvolvimento local, o que deverá ser feito num contexto multidisciplinar, de vez que, pela delimitação tradicional entre as ciências, não é possível tratar de assuntos relativos ao processo de desenvolvimento nos estritos marcos de uma delas somente.

\section{REFERENCIAS}

ABDALLA, M. M.; FARIA, A. A. Repensando Desenvolvimento Local e o Problema das Cidades Orientadas ao Mercado. In: SOCIETY FOR SOCIAL STUDIES OF SCIENCE (4S), 2014, Buenos Aires. Proceedings... Buenos Aires: ESOCITE, 2014

AROCENA, J. El desarrolo local, un desafio contemporáneo. Venezuela: Centro Latinoamericano de Economía Humana, 1995.

AROCENA, J. Lo global y lo local en la transición conteporánea. Cuadernos del claeh, v. 2, n. 20, 1997. Pp. 2-20.

BECKER, D. F. Capital social: um "novo" (velho) paradigma de organização social dos diferentes processos de desenvolvimento regional. Estudo \& Debate, Lajeado, ano 9, n. 1, p. 7-26, 2002.

BOISIER. S. Desarrollo (local): ¿ de qué estamos habalndo? In.: MADOERY; OSCAR e VÁZQUES BARQUERO, A. (Orgs.), Transformaciones globales, Instituciones y

Políticas de desarrollo local. Editorial Homo Sapiens: Rosario, 2001.

BOISIER. S. Desarrollo territorial y descentralización: el desarrolho em el lugar y em las manos de la gente. Revista eure, vol. XXX, n. 90, septiembre, Santiago de Chile, 2004, pp. 27-40. 
BOISIER. S. América Latina em um médio siglo (1950/2000): el desarrollo, ¿ donde estuvo? Observatório iberoamericano del desarrollo local y la economia social. Ano 1 n. 1. Julio-septiembre, 2007, pp.3-41.

BOUDEVILLE, Jacques-R. Les spaces économiques. Press Universitaires de France, Paris, 1970.

BOURDIEU, P. O Poder simbólico. Lisboa: Difel; Rio de Janeiro: Bertrand Brasil, 1989.

BOURDIEU, P. O capital social: notas provisórias. In: NOGUEIRA, Maria Alice; CATANI, Afrânio (Org.). Escritos de educação. Petrópolis: Vozes, 1998. p. 65-69.

BREITBACH, A. C. M. Estudo sobre o conceito de Região. 121f. Dissertação (Mestrado em Planejamento Urbano e Regional). Faculdade de Arquitetura. UFGS, Porto Alegre, 1986.

BRITO, S. P. A Sociologia e a abordagem sistêmica. São Paulo: Papirus, 1986.

CAPRA, F. O ponto de mutação: a ciência, a sociedade e a cultura emergente. São Paulo: Cultrix, 1982.

CHRISTALLER, W. Central places in southern Germany. New Jersey: Englewood Cliffs, 1933. p. 27-83.

COLEMAN, J. S. Foundations of social theory. Cambridge; Massachusetts; London: The Belknap Press of Havard University Press, 1990. P.300-321. Disponível em: http://sisphd.wikispaces.com/file/view/Coleman-Foundations+of+Social+Theorych+12.PDF. Acesso em: 24 ago. 2018

COLEMAN, J. S. Social capital in the creation of human capital. American Journal of Sociology, Chicago, v. 94, p. 95-120, 1998. Supplement.

<http://www.econ.msu.ru/cmt2/lib/c/477/File/Social\%20Capital\%20in\%20the\%20Creati on\%200f\%20Human\%20Capital.pdf> Acesso em 20 ago. 2018.

ENRÍQUEZ, V. A. Desarrolo económico local: definición, alcances y perspectivas em América Latina. Perú: Condesan. 2011.

FERREIRA, M. T. S. et al. Análise do desenvolvimento de Arranjos Produtivos Locais (APLs): um estudo de caso do município de Paraty (RJ). Revista de Administração pública. RAP - Rio de Janeiro, v. 45. n 2, mar./abr. 2011, pp. 517-539.

FERRERA DE LIMA, J. A concepção do espaço econômico polarizado. Revista Internacional de Desenvolvimento Local. v. 4, n. 7, p. 7-14, Set. 2003. 
FERRERA DE LIMA, J. La Diffusion Spatiale du Développement Économique Regional: L'analyse des composantes du changement spatial dans la région Sud du Brésil. Sarrebruck: Éditions universitaires européennes, 2010. v. 01. 179 p.

FIGUEIRA, E. Capital Social e o Processo de Participação no Desenvolvimento Local. Fluxos \& Riscos, n. 2, 2011, pp 19-27.

FIGUEIRA, E. Desenvolvimento Local, Ruralidade e Regionalização: Problemáticas analisadas a partir das realidades Alentejans. Lisboa: Amazon, 2017.

FUKUYAMA, F. “Capital Social”. In: HARRISON, L. E.; HUNTINGTON, S. P. A cultura importa. Rio de Janeiro: Record, 2002.

FURTADO, C. O mito do desenvolvimento. São Paulo: Paz e Terra, 1996. 96p.

HARVEY, D. Os limites do capital. São Paulo: Boitempo. 2013.

HOOVER, E. M. Location theory and shoe and leather industries. Cambriedge, Mass: Harvard University Press. 1937.

ISARD, W. Location and space-economy: a general theory relating to industrial location, market areas, land use, trade and urban structure. Cambridge: MIT, 1956. $350 p$.

LEME, R. Contribuições à teoria da localização industrial. São Paulo: USP/IPE, 1982. 387p.

LEMOS, M. B. Espaço e capital: um estudo sobre a dinâmica centro X periferia. 1988. 2v. Tese (Doutorado em Economia) - Instituto de Economia, Universidade Estadual de Campinas, Campinas, 1988

LEROY, J. Modelos de desenvolvimento em questão. In: Comissão Pastoral da Terra. A luta pela terra. São Paulo: Paulus, 1997. p. 87-98.

LÖSCH, A. The economics of location. New Haven: Yale University Press, 1954. p.103-138. (Primeira edição: 1940).

LOPES, A.S. Desenvolvimento Regional: problemática, teoria e modelos. Lisboa: Fundação Calouste Gulbenkian, 2. ed. 1984, p. 2-35.

MARSHALL, A. Princípios de economia. São Paulo: Abril cultural, 1982. 2v. (Os economistas; Primeira edição: 1890).

MARTÍN, J. C. Los retos por una sociedad a escala humana: el desarrollo local. In: SOUZA, M. A. Metrópole e globalização: conhecendo a cidade de São Paulo. São Paulo: CEDESP, 1999. p. 169-177. 
MARTINS, S. R. O. Desenvolvimento Local: questões conceituais e metodológicas. INTERAÇÕES Revista Internacional de Desenvolvimento Local. Vol. 3, N.5, p. 51-59, set. 2002.

MARX, K. O Capital: crítica da economia política. v. I. Tradução de Regis Barbosa e Flávio R. Kothe. São Paulo: Nova Cultural, 1996. (Coleção os Economistas).

MAX-NEEF, M.; ELIZALDE, A.; HOPENHAYN, M. Desarrollo a escala humana: una opción para el futuro. In: Development Dialogue (número especial). Santiago do Chile, 1986.

MBALLA, L.V. Desarrollo local y microfinanzas como estrategias de atención a las necessidades sociales: un acercamiento teórico conceptual. Revista Mexicana de Ciencias Políticas y Sociles. Ano LXII, n, 229, enero-abril, 2017. Pp 101-128.

MOURA, M.S. et al. Desenvolvimento local sustentável: o que sinalizam as práticas. In: Encontro da Associação Nacional de Pós-Graduação e Pesquisa em Administração, 2002, Salvador. Anais... Salvador: Anpad, 2003. 1 CD.

OLIVEIRA, N.M; PIFFER, M. Conjuntura do desenvolvimento regional dos municípios do Estado do Tocantins. Desenvolvimento Regional em debate: Revista eletrônica do Programa de Mestrado em Desenvolvimento regional da Universidade de Contestado. Vol. 6, n. 3, p. 32-61, nov. 2016.

PALACIOS, J. J. El concepto de región: la dimensión espacial de los processos sociales. Revista Interamericana de Planificación. México. Sociedad Interamericana de Planificación. v.17, n.66, 1983, pp.56-58.

PAUNERO, F.X.; SÁNCHEZ, D.; CORONA, L. T. Sistemas productivos locales en México. Economía Informa, v. 345, 2007, pp 216-237.

PERROUX, F. Note sur la notion de póle de croissance. Tradução com permissão da Revista Brasileira de Estudos Políticos. Economie appliquée, 1955.

PIFFER, M. et al. Desenvolvimento regional do Oeste Paranaense a partir do capital social. [s.l.], 2007. Disponível em: <

http://www.capitalsocialsul.com.br/capitalsocialsul/desenvolvimentoregional/Grupo \%203/14.pdf. Acesso em: 25 jul. 2018.

PIKE, A. RODRIGUEZ-POSE, A. TOMANEY, J. Local and Regional Development. Journal of Economic Geography, v.7, n.2, 2007, pp. 217-219.

PUTNAM, R. Comunidade e democracia: a experiência da Itália moderna. Rio de Janeiro: FGV, 2007.

SEN, A. Desenvolvimento como liberdade. $1^{\text {a }}$ ed., São Paulo: Companhia das Letras, 2000. 
SEN, A. Desigualdade reexaminada. $2^{\text {a }}$ ed., Rio de Janeiro: Record, 2008.

SIMÕES, R. F. Localização industrial e relações intersetoriais: uma análise de fuzzy cluster para Minas Gerais. 176f. Tese (Doutorado em Economia). Instituto de Economia da Universidade Estadual de Campinas. 2003

VÁZQUEZ BARQUERO, A. Desenvolvimento Local: novas dinâmicas na acumulação e regulação do capital. Ensaios FEE, Porto Alegre, v. 16, n. 1, 1995, pp. 222-241.

VÁSQUEZ BARQUERO, A. Desenvolvimento endógeno em tempos de globalização. Porto Alegre: Editora da UFRGS, 2002.

VAZQUEZ-BARQUERO, A. Desarrollo Local: Una estrategia para tiempos de crisis. Conceptos criticos. Universitas Forum, Vol. 1, n. 2, May 2009.

VERHELST, Thierry G. O direito à diferença. Petrópolis: Vozes, 1992.

WEBER, Alfred. The theory of the location of industries. Chicago: University of Chicago Press, 1957. (primeira edição: 1909).

Nilton Marques de Oliveira. Economista pela UEM, Mestre em Economia Aplicada pela UFV e Doutor em Desenvolvimento Regional e Agronegócio pela UNIOESTE, Toledo - PR. Professor do Programa de Pós-graduação em Desenvolvimento Regional e do curso de Ciências Econômica da Universidade Federal do Tocantins - UFT. Lider do Grupo de Pesquisa em Desenvolvimento Regional e Territorial do Centro Norte do Brasil (DRT - Centro Norte). niltonmarques@uft.edu.br

Como citar: OLIVEIRA, Nilton Marques de. Desenvolvimento Local: Quo Vadis?. Redes (St. Cruz Sul, Online), Santa Cruz do Sul, v. 25, p. 1698-1714, nov. 2020. ISSN 1982-6745. doi:https://doi.org/10.17058/redes.v25i4.13911.

Fontes de financiamento: "O presente trabalho foi realizado com apoio da Coordenação de Aperfeiçoamento de Pessoal de Nível Superior - Brasil (CAPES) - Código de Financiamento 001. 